\title{
The generation of a mathematical model of the biogas production process from organic municipal solid waste
}

\author{
Marzhan Temirbekova ${ }^{1}$, Madina Aliyarova ${ }^{1}$, Iliya Iliev $^{2 *}$, Aliya Yelemanova $^{1}$, and Saule \\ Sagintayeva $^{1}$ \\ ${ }^{1}$ AUPET named after G. Daukeev, 050000 Almaty, Kazakhstan \\ ${ }^{2}$ University of Ruse, Department of Thermotechnics, Hydraulics and Environmental Engineering \\ 7017 Ruse, 8 Studentska Str., Bulgaria
}

\begin{abstract}
This paper justifies the efficiency of the biogas collection and utilization at the MSW (municipal solid waste) landfill in Almaty with the installation of several modern biogas plants. The optimal mode of processes occurring in a biogas plant is determined by computer generated simulations. Mathematical model parameters were identified to describe biochemical processes occurring in a biogas plant. Two approaches are used to resolve the mathematical model: the finite-difference method for solving the system of differential equations and simulation modeling by using the Any Logic package. A program is written in the algorithmic language $\mathrm{C}++$. Numerous calculations were carried out, the results of which are presented in curves and their qualitative picture is consistent with the ongoing processes. The created computer program allows to make a preliminary forecast of anaerobic fermentation occurring in the bioreactor depending on volume of the substrate, methane microorganisms and temperature conditions.
\end{abstract}

\section{Introduction}

The Joint Stock Company «Tartip», is engaged in the collection, recycling and disposal of municipal solid waste in the city of Almaty, a large metropolis of the Republic of Kazakhstan. The organization of household waste removing and its scientific-based recycling is a topical issue. Environmental conservation is one of the major challenges of our time. The JSC «Tartip» has 200 units of special-purpose machines, located at seven production capacities in six urban districts. The motor traffic is controlled by using the GPS monitoring system to ensure the timely removal, improve the speed and to optimize the logistics of removal routes. The Company carries out work on the municipal solid waste (MSW) and other waste removing as carefully as possible, without harming the

\footnotetext{
*Corresponding author: iiliev@enconservices.com
} 
environment. More than 2,000 tons of garbage are dumping daily in Almaty, which must be collected and removed out of the city. The JSC «Tartip» constantly improves the processes being carried out, gives priority to preventive measures to prevent or minimize pollution on the environment and energy usage reducing, and also the Company conducts open and transparent activities [1].

In accordance with practice all over the world, several options can be proposed for the biogas collection and disposal at the municipal solid waste (MSW) landfill in Almaty, which is the largest waste disposal site serving the city and villages in the surrounding area. About 13.5 million tons of waste has been accumulated within this landfill, from which $1740 \mathrm{~m}^{3} / \mathrm{h}$ of biogas can be produced.

In connection with this, the most attractive projects are the biogas production. For this purpose, it is sufficient to install several biogas plants. In this work, based on the wellknown mathematical models and Any Logic simulation modelling, computer programs were created for preliminary forecast of the anaerobic fermentation process in biogas units with overpressure protection and a combined frame-blade structure of an anchor type agitator with fully automatic electric drive $[2,8]$.

\section{Mathematical model}

The morphological composition of waste was obtained as a result of time - studying for Almaty. The morphological composition studies of waste in Almaty, shows that food waste is about 30\% [3]. Table 1 presents the Morphological composition of waste in Almaty.

Table 1. Morphological composition of waste in Almaty

\begin{tabular}{|l|c|c|c|}
\hline Component name & Almaty, 2008 (\%) & Almaty, 2012 (\%) & $\begin{array}{l}\text { Arithmetic mean } \\
\text { value (\%) }\end{array}$ \\
\hline Food waste & 32.50 & 23.40 & 27.95 \\
\hline $\begin{array}{l}\text { Paper and cardboard } \\
\text { paper }\end{array}$ & 27.60 & 27.80 & 27.70 \\
\hline $\begin{array}{l}\text { Park and garden } \\
\text { waste }\end{array}$ & 0.00 & 0.00 & 0.00 \\
\hline Wood waste & 1.20 & 2.40 & 1.80 \\
\hline $\begin{array}{l}\text { Rubber, leather, } \\
\text { bones }\end{array}$ & 0.70 & 0.04 & 0.37 \\
\hline Textile material & 2.40 & 1.30 & 1.85 \\
\hline Other organic waste* & 4.30 & 5.53 & 11.30 \\
\hline Plastic material & 8.30 & 14.30 & 2.25 \\
\hline Metal & 2.90 & 1.60 & 6.45 \\
\hline Glass & 4.30 & 8.60 & 10.10 \\
\hline Construction debris & 10.80 & 9.40 & 0.35 \\
\hline Stone screening dust & 0.70 & 0.00 & 4.92 \\
\hline Inorganic waste* & 4.30 & 5.53 & 100 \\
\hline Total & 100 & 100 & 64.6 \\
\hline $\begin{array}{l}\text { The sum of an } \\
\text { organic components }\end{array}$ & 68.7 & 60.5 & 35.4 \\
\hline $\begin{array}{l}\text { The sum of an } \\
\text { inorganic } \\
\text { components }\end{array}$ & 31.3 & 39.5 & \\
\hline
\end{tabular}


As the table shows, the significant specific gravity of food waste once again confirms the effectiveness of the biogas plants.

Mathematical and computer simulations using mathematical models are the most efficient ways of conducting simulation experiments, as they are less expensive compared to fullscale experiments. In the papers of L.I. Ruzhinskaya and A.A. Fomenkov, the analysis of known models of organic matter anaerobic fermentation with the biogas production is executed. The models that are often used in the references describing the kinetics of methane fermentation and the parameters of the kinetic process are demonstrated. Different models describe the growth and development of micro population, the components degeneration, and the preparation of products in an anaerobic bioreactor [4,10,11]. There are papers related to simulated exponential curves, the modified Gompertz curves of the biogas production process from MSW in anaerobic reactors [5]. In addition, models are generated for the biogas production process optimization, comprehensive models including the microbial flora growth kinetics, which take into account various charging mechanisms and time frame, temperature of process and inhibitory effects [6].

In the papers of A. G. Topage, V.A. Wigant, L.A. Khvorov [7] the mathematical model is shown as an ordinary differential system with initial conditions. For simulation, the Any Logic simulation process package is used.

Consider the following task [7,9] for modeling the process of biofuel production from organic municipal waste:

where

$$
\begin{aligned}
& \frac{\partial W_{i}}{\partial t}=-k_{i} \cdot W_{i} \cdot f_{H}(S), i=1, \ldots, M, \quad W(0)=W_{0}, \\
& \frac{\partial S}{\partial t}=\gamma \sum_{i=1}^{M} k_{i} \cdot W_{i} \cdot f_{H}(S)-\rho_{M} \cdot f_{M}(S) \cdot \frac{S \cdot B}{K_{S}+S}, S(0)=0, \\
& \frac{\partial P}{\partial t}=Y \cdot(1-\theta) \cdot \rho_{M} \cdot f_{M}(S) \cdot \frac{S \cdot B}{K_{S}+S}, P(0)=0, \\
& \frac{\partial B}{\partial t}=\theta \cdot \rho_{M} \cdot f_{M}(S) \cdot \frac{S \cdot B}{K_{S}+S}-K_{D} \cdot B, B(0)=B_{0} \\
& f_{H}(S)=\left(1+\left(\frac{S}{A_{H}}\right)^{N_{H}}\right)^{-1} \\
& f_{H}(S)=\left(1+\left(\frac{S}{A_{M}}\right)^{N_{M}}\right)^{-1} .
\end{aligned}
$$

$W$ - is the initial substrate concentration $(g / l)$;

$S$ - is the hydrolysis product concentration $(g / l)$;

$W_{i}$ is the vector components of the various types raw material concentrations;

$P$ - is the total biogas yield, $(g / l)$;

$k-$ is the hydrolysis kinetic constant;

$k_{i}-i$ s the hydrolysis kinetic constants specific to $W_{i}$ types;

$M$ - is the number of considered raw material types (in this case 3);

$B-$ is the concentration of the methane microorganisms in biomass;

$\gamma-$ is the conversion coefficient of the substrate into fatty acids (stoichiometric coefficient);

$\rho_{M}$ - is the methanogenesis maximum specific rate in the terms of the volatile fatty acid biomass utilization;

$K_{s}-$ is the half saturation constant in the Monod equation for the methanogenesis intensity;

$(I-\Theta)$ - is the substrate fraction used for biogas formation;

$Y-$ is the conversion coefficient of the fatty acids utilization flow to final product yield units (biogas); 
$K_{D^{-}}$is the decay factor;

$f_{H}(S)$ and $f_{M}(S)$ - are describe the hydrolysis reactions inhibition and the microbial fermentation process by fatty acids (acidification).

The values of the constant coefficients used in the model (1) are given in the form of a system and dynamic table in the paper [7]. Using model (1), we generate a model in Any Logic. The simulation model and curves of the key process indicators are given in Figure 1. In Fig. 1, the concentrations of various types of feedstock in the form of the $\mathrm{W}_{\mathrm{i}}$ vector components are indicated through $\mathrm{W} 1, \mathrm{~W} 2, \mathrm{~W} 3$.

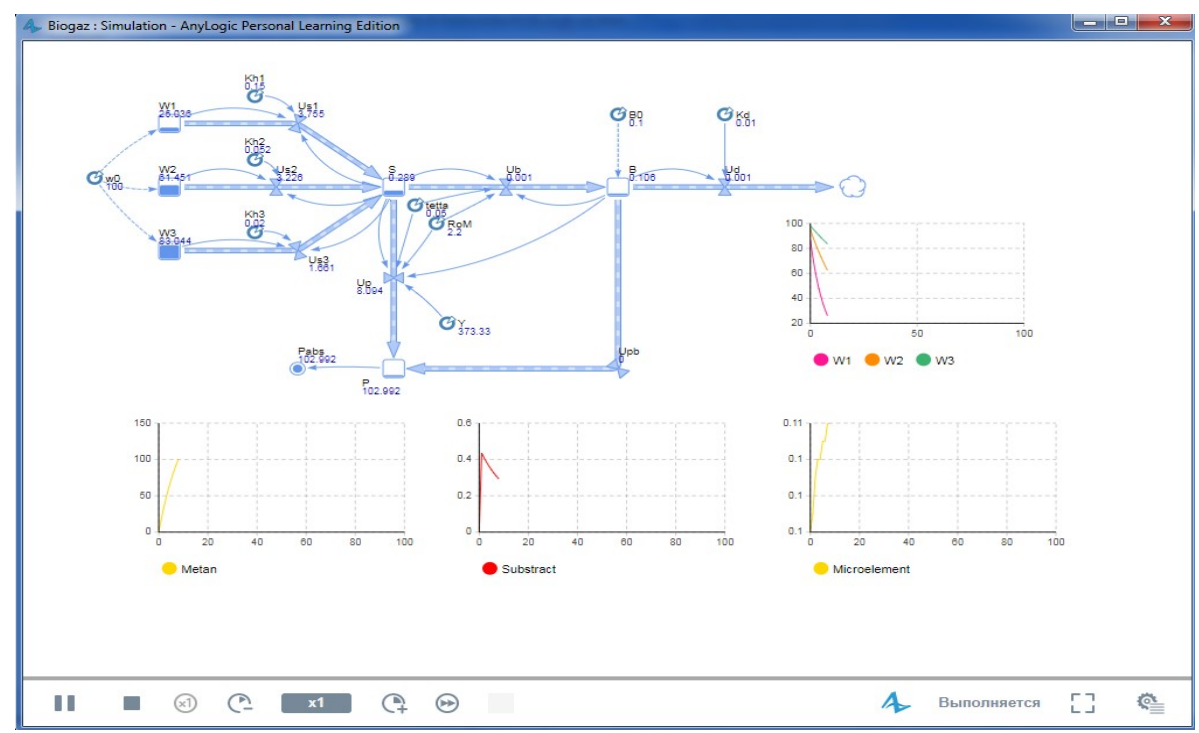

Fig.1. The biogas model generated in Any Logic

For the model generation, the «days» unit of time was selected, since all the coefficients are given in the 1 / day format. For the differential equation system (1) a corresponding semi-implicit difference scheme of the following form has been built:

$$
\begin{aligned}
& W_{i}^{n+1}=W_{i}^{n+1}-\tau \cdot k_{i} \cdot W_{i}^{n} \cdot f_{H}\left(S^{n}\right), \quad i=1,2,3, \\
& S^{n+1}=S^{n}+\tau \cdot\left(\gamma \sum_{i=1}^{3} k_{i} \cdot W_{i}^{n} \cdot f_{H}\left(S^{n}\right)-\rho_{M} \cdot f_{M}\left(S^{n}\right) \cdot \frac{S^{n} \cdot B^{n}}{K_{S}+S^{n}}\right) \\
& P^{n+1}=P^{n}+\tau \cdot\left(Y \cdot(1-\theta) \cdot \rho_{M} \cdot f_{M}\left(S^{n+1}\right) \cdot \frac{S^{n+1} \cdot B^{n}}{K_{S}+S^{n+1}}\right) \\
& B^{n+1}=B^{n}+\tau \cdot\left(\theta \cdot \rho_{M} \cdot f_{M}\left(S^{n+1}\right) \cdot \frac{S^{n+1} \cdot B^{n}}{K_{S}+S^{n+1}}-K_{D} B^{n}\right) \\
& n=1,2,3, \ldots, N .
\end{aligned}
$$

For the numerical solution of difference equations, a program has been developed using the algorithmic language $\mathrm{C}++$. Unknown values of the concentration vector of the source feedstock of various types are specified in the form of a one-dimensional array, the concentration of hydrolysis products, i.e. the total biogas yield, the biomass concentration 
of methanogenic microorganisms, are considered in the program as variables depending on the discrete time. Based on the given values of initial conditions, the desired values are calculated according to recursive formulas (2) depending on time. Then the calculated results are imported into a graphical editor to build graphs.

The identification of the coefficients included in the mathematical model was carried out through a computing experiment. Numerical computations on the mathematical model (1) may be performed in a wide range of $\tau$ time step and equation coefficients meeting the stability conditions of the difference scheme (2). Therefore, it is necessary to determine the value of the time step corresponding to real time.

By using the initial conditions $W_{0}=100 \mathrm{~g} / 1, B_{0}=0.1 \mathrm{~g} / 1$, we obtain the $P, S, B$ dynamic pattern which are written as the following curves (Figure 2). In this point, at the grid step of $\tau=0.01$ and $\mathrm{N}=50,000$, gives a result corresponding to 500 days.

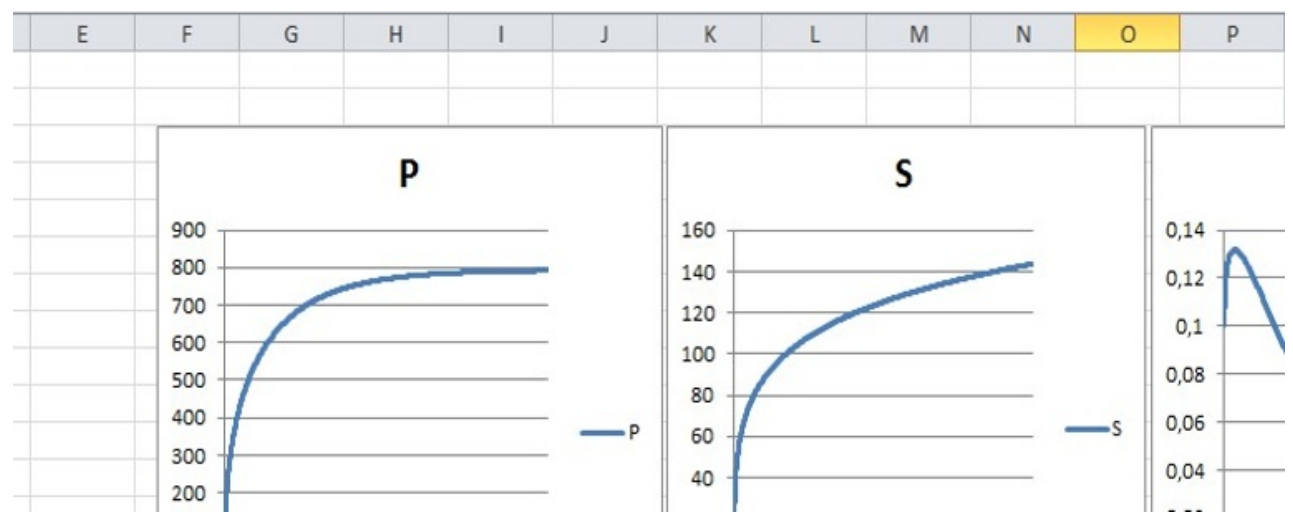

Fig. 2. Change of $P$ - is the total biogas yield (g/1), $S$ is the hydrolysis product concentration (g/1) $B$ - is the concentration of the methane microorganisms in biomass

Set the value $\gamma=0.32$, and $Y=0.85$, and obtain the values of the total biogas yield, the hydrolysis product concentration, and the methane microorganisms biomass concentration in 500 days.
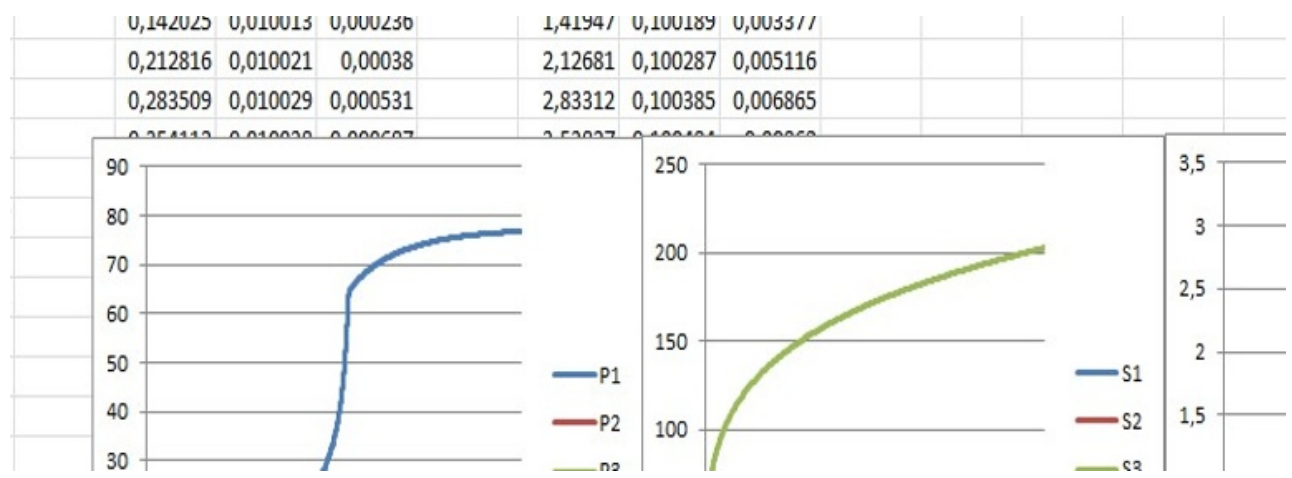

Fig.3. The methane yield $(P)$, hydrolysis product concentration $(S)$ and $(B)$-concentration of methanogenic bacterium changes. 
The blue lines in the figure show the curves corresponding to the $W_{0}=300 \mathrm{~g} / 1, \mathrm{~B}_{0}=0.3$ $\mathrm{g} / 1$ initial values. Under these conditions, the reactor is operating normally.

If too few methane microorganisms are introduced (red line, $W_{0}=300 \mathrm{~g} / 1, B_{0}=0.005 \mathrm{~g}$ $/ 1$, the cork effect is observed in this case. If too much organic raw material is introduced, $W_{0}=1000 \mathrm{~g} / 1, B_{0}=0.2 \mathrm{~g} / 1$, then the curve will be such as shown by the green line (Figure 3).

\section{Conclusions}

Thus, developed software product in the $\mathrm{C}++$ algorithmic language and simulation model using Any Logic created on the basis of a mathematical model in the form of a system of ordinary differential equations allow to carry out numerous computing experiments to simulate various scenarios of processes in biogas units. The software products developed by the authors of the article have been tested on previously known test examples. The correspondence of the non-dimensional time step to real time has been established and computing experiments have been carried out to identify other coefficients of the equations. The created set of application programs allows to make a preliminary and predictive computer modeling of the process of biogas production from various morphological composition of organic waste.

\section{References}

1. Web site: www.tartyp.kz/o-nas/

2. S.A. Keshuov, V.I. Barkov, A.B. Tokmoldayev, The biogas plants application in livestock business, Almaty, (2012)

3. Zh.M. Zhapparova, EcoInform, Materials of the $\mathbf{5}^{\text {th }}$ International Conference "Cooperation for Solving the Waste Challenge", 195-197, (2008)

4. L. I. Ruzhinskaya, A. A. Fomenkova, Scientific Journal «Science rise» №4/2(4), 63-69, (2014)

5. H.M. Lo, T.A. Kurniawan, M.E.T. Sillanpää, T.Y. Pai, C.F. Chiang, K.P. Chao, M.H. Liu, S.H. Chuang, C.J. Banks, S.C. Wang, K.C. Lin, C.Y. Lin, W.F. Liu, P.H. Cheng, C.K. Chen, H.Y. Chiu, H.Y. Wu, Bioresource Technology, Volume 101, Issue 16, 6329-6335, (2010)

6. Mandy Gerber, Roland Span, An Analysis of Available Mathematical Models for Anaerobic Digestion of Organic Substances for Production of Biogas, IGRC, (2008)

7. A. G. Topage, V. A. Vigant, L. A. Khvorova, Chemistry of vegetable raw material, No. 1, 171-184, (2018)

8. I. K. Iliev, V. I. Kamburova, A. K. Terziev, Analyses of landfill gas potential in Bulgaria. IN: EEA \& AE 2013- International Scientific Conference 17-18.05.2013, Ruse, Bulgaria, Printing Centre at Ruse University, 230-235, (2013)

9. V. I. Kamburova, I. K. Iliev, A. K. Terziev. Schemes for project financing of combined heat and power production through biomass gasification. IN: $3^{\text {rd }}$ International Conference of Thermal Equipment, Renewable Energy and Rural Development, Mamaia-Romania 1214 June 2014 (the best paper), Politehnica Press, 65-71 (2014)

10. Dimitrov R., Zlateva P. Possible Uses of Biogas for Power Purposes, IN: BulEF-2019$11^{\text {th }}$ Electrical Engineering Faculty Conference, 1-4, (2019)

11. Dimitrov R., Ivanov Z., Zlateva P., Mihaylov V. Optimization of biogas composition in experimental studies. $8^{\text {th }}$ International Conference on TE-RE-RD 2019, E3S Web of Conferences, vol. 112, (2019) 
